\title{
Getting it right the first time
}

Financial penalties to improve disability benefit assessments

\author{
Evan Odell
}

2020-05-30

\section{Contents}

1 Introduction 2

2 Disability benefits in the UK 3

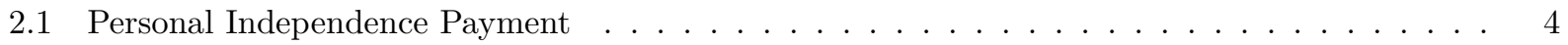

2.2 Employment and Support Allowance . . . . . . . . . . . . . . . . . . . . . . 6

2.2.1 The Work Capability Assessment . . . . . . . . . . . . . . . . . . 6

2.3 Scepticism and Hostility . . . . . . . . . . . . . . . . . . . . . . . . . . 6

2.4 Accuracy and Accountability . . . . . . . . . . . . . . . . . . . . . 8

2.5 Application and Appeals . . . . . . . . . . . . . . . . . . . . . . . . . . . . . 8

2.6 Chokepoints . . . . . . . . . . . . . . . . . . . . . . . 12

2.7 Success on Appeal . . . . . . . . . . . . . . . . . . . . . . . . . . . 12

$2.7 .1 \mathrm{ESA} \ldots \ldots \ldots \ldots \ldots \ldots \ldots \ldots \ldots \ldots$

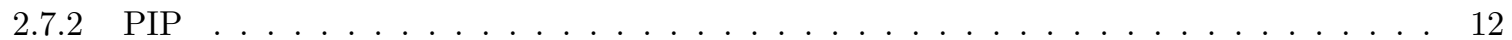

2.8 Clearance Times . . . . . . . . . . . . . . . . . . . . . . . 15

3 Why compensate? 15

3.1 Compensation eligibility . . . . . . . . . . . . . . . . . . . . . 15

3.2 Incentives for Accuracy . . . . . . . . . . . . . . . . . . . . . . . 16

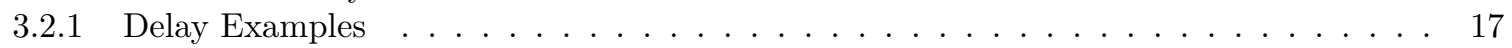

3.2.2 Compensation rates and personal debt costs . . . . . . . . . . . . . . . . . 18

4 Conclusion 18

\begin{tabular}{ll} 
References & 18 \\
\hline
\end{tabular}

\section{List of Tables}

1 Personal Independence Payment Award Rates . . . . . . . . . . . . . . . . . . . . 5

2 DWP's cost-per-appeal . . . . . . . . . . . . . . . . . . . . . 17

\section{List of Figures}

1 Percentage of one group of working-age disability benefit recipients receiving the other type of working-age disability benefit . . . . . . . . . . . . . . . . . . . . . . . .

2 Total of one group of working-age disability benefit recipients receiving the other type of working-age disability benefit . . . . . . . . . . . . . . . . . . . . . . . . 4 4

3 Percentage of one group of working-age disability benefit recipients receiving the other type of working-age disability benefit, by UK region . . . . . . . . . . . . . . . . . . . 5

$4 \quad$ ESA Group Assignment, by Medical Condition and Initial or Repeat Assessment . . . . . . . 7 
5 Overall Success Rate on PIP Applications by Main Disability Category . . . . . . . . . 8

6 Overall Success Rate on PIP Applications, April 2013 - April 2019 . . . . . . . . . . . . . . . 9

7 DWP PIP Award Rates by Major Disability Category . . . . . . . . . . . . . . . . . . 10

8 Caseload Distribution, First Tier Social Security Tribunals . . . . . . . . . . . . . . . . . 11

9 Caseload Totals, First Tier Social Security Tribunals . . . . . . . . . . . . . . . . . . . 11

10 Employment and Support Allowance Appeal Overturn Rates . . . . . . . . . . . . . . . . . 13

11 Employment and Support Allowance Appeal Outcomes _ . . . . . . . . . . . . . . . . . 13

12 ESA Outcomes Before and After Appeal . . . . . . . . . . . . . . . . . . . . . . . . . 14

13 Total ESA group placements before and after appeal . . . . . . . . . . . . . . . . . . . 14

14 Personal Independent Payment Appeal Overturn Rates . . . . . . . . . . . . . . . . . . . 15

15 Average First Tier Tribunal Clearance Times . . . . . . . . . . . . . . . . . . . . 16

\section{Introduction}

Welfare state benefits (including services and cash payments) can be divided up into four general categories:

1. Universal benefits

2. Contributory benefits

3. Means-tested benefits

4. Needs-tested benefits

Disability benefits rely on a mixture of means-testing and needs-testing to determine eligibility. The needstesting process varies between welfare states, but can involve examination of existing medical records, written testimony from healthcare providers, an in-person assessment of applicants, or some combination thereof. The needs-testing component of the system needs to be transparent to both applicants and the public, be capable of providing people with disabilities and health conditions sufficient support to take part in society on an equal basis with others, and reflective of the actual social and economic conditions that its prospective beneficiaries are living in. This paper focuses on the UK, but the problem of inaccurate and unaccountable eligbility procedures is present in other welfare states (for example see Benitez-Silva, Buchinsky, and Rust 2004 on the American SSDI system).

Means-tested benefits rely on "objective" criteria that is typically easy to measure, such as income, assets and household size. Eligibility for contributory benefits is based on what a person has paid into a system, indirectly through measuring hours or years worked, or directly by calculating the value of contributions made to an insurance scheme. For example, in most welfare states pension eligibility is determined by a combination of age and years worked, with additional financial support available for pensioners whose income falls below a given threshold. Universal benefits are available to anyone who asks for them, regardless of their circumstances (Titmuss [1968] 2006), such as healthcare or education.

Unlike means-tested and contributory benefits, determining eligibility through needs-tested involves a high degree of subjectivity. Needs-tested disability benefits generally fit into two categories: a) to provide compensation for the additional costs and barriers faced by disabled people and b) to provide financial support for people unable to work because of their health or disability.

Disability, even severe disability, is not neccessarily an inherent barrier to employment. An individual's skills, qualifications, geographic location, age and employment status when disability was acquired, the specific type of disability or health condition, as well as background economic conditions, labour market practices and workplace reasonable adjustment rules all influence the possibility of a disabled person taking part in paid employment. Moreover for some people taking part in paid employment is not a positive outcome and will exacerbate their disability or health condition. Needs-tested assessments can ignore these "real world" variables in favour of a functional assessment of a person's physical and mental condition, although some welfare states do attempt to incorporate social and economic context, with varrying degrees of success (Baumberg Geiger et al. 2015, 35-51).

Measuring the direct and indirect financial costs of a disability produces varying results, depending on the assumptions made (see Heslop 2013, 10-12 for an overview of the challenges of costing disability). Work 
carried out for the charity Scope by John, Thomas, and Touchet (2019) found an average additional cost of $£ 583$ per month associated with having a disability in the UK.

Low accuracy in disability benefit assessments can potentially undermine public trust in the fairness of the welfare state, both through high rates of (possibly) fraudulent claims, and through unfair denial of benefits to those who qualify. Low accuracy rates can produce additional costs for the welfare state - such as additional demand for healthcare services - and cause harm to wrongfully denied claimants. Claimants may go into debt, and be unable to access other services or benefits that use receipt of other benefits to determine elegibility, such as social care or blue badge parking.

This paper explores the problem of low accuracy in disability benefit assessments, using the UK as an example. The UK's disability benefits system has been subject to substantial reforms in the previous decade, and continues to be in flux. I suggest the introduction of financial incentives to shift the assessment process towards treating claimants' statements at face value (and running the risk of false positives), away from the current practice of treating all claimants with scepticism (and running the risk of false negatives).

\section{Disability benefits in the UK}

There are two key working-age disability benefits in the UK: Employment and Support Allowance (ESA), and Personal Independence Payment (PIP). ESA provides financial support for people unable to work because of their disability or health condition, along with additional support for people deemed disabled but still able to work. ESA is a means tested benefit, and takes into account savings, and the income of an applicant's partner. PIP is not means tested, and eligibility is basedon a functional assessment, and the benefit is intended to financial support to manage the costs of having a disability or health condition.
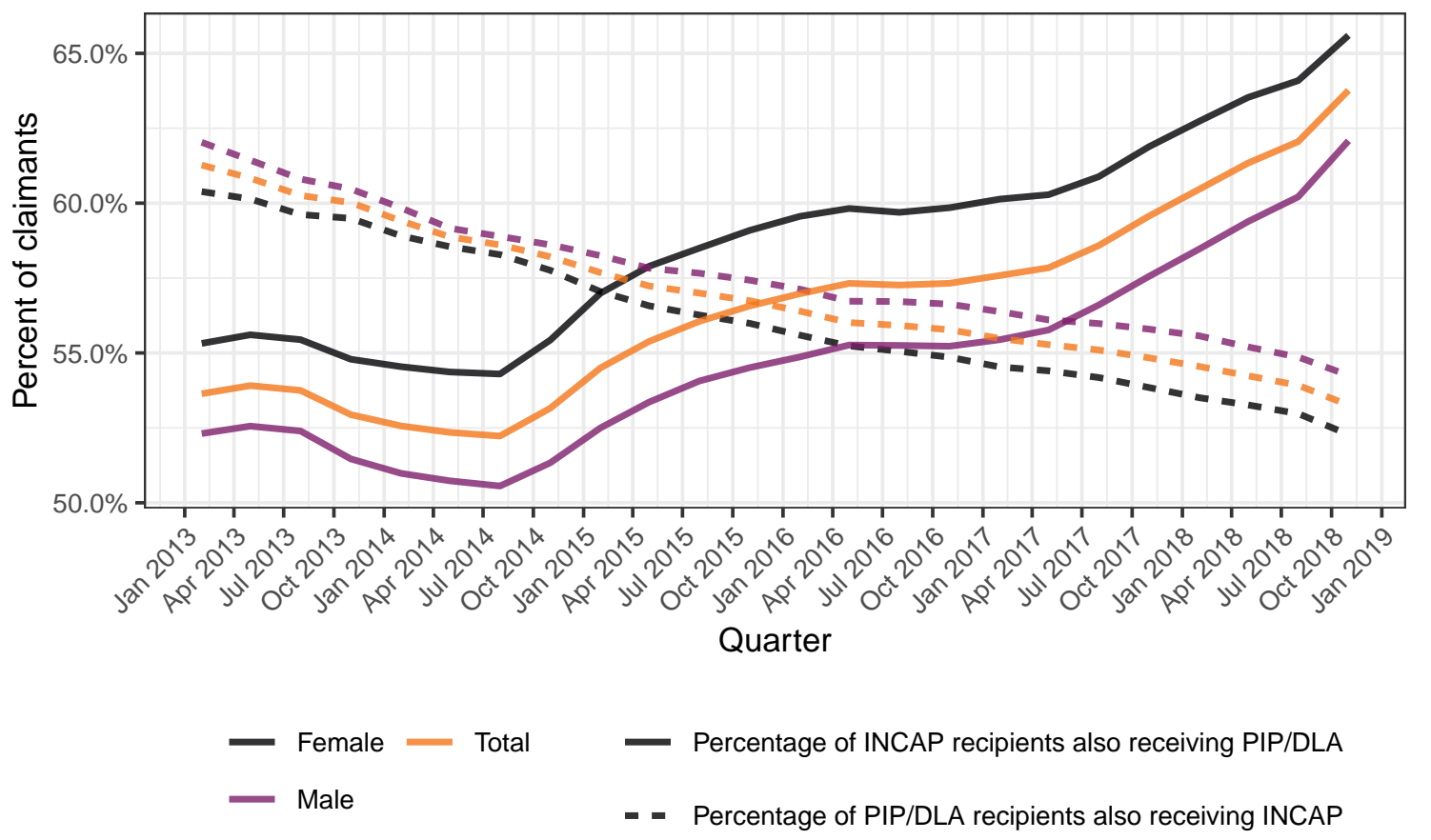

(c) Evan Odell | 2019 | CC-BY-SA

Figure 1: Percentage of one group of working-age disability benefit recipients receiving the other type of working-age disability benefit

The two benefits are not mutually exclusive, and many people (see Figures 1 and 2) receive both. In the most recent quarter available (November 2018) 912,948 people were in receipt of incapacity benefits (ESA, and any legacy claimaints of older incapacity benefits not yet moved to ESA). 582,153 of those claimants, 


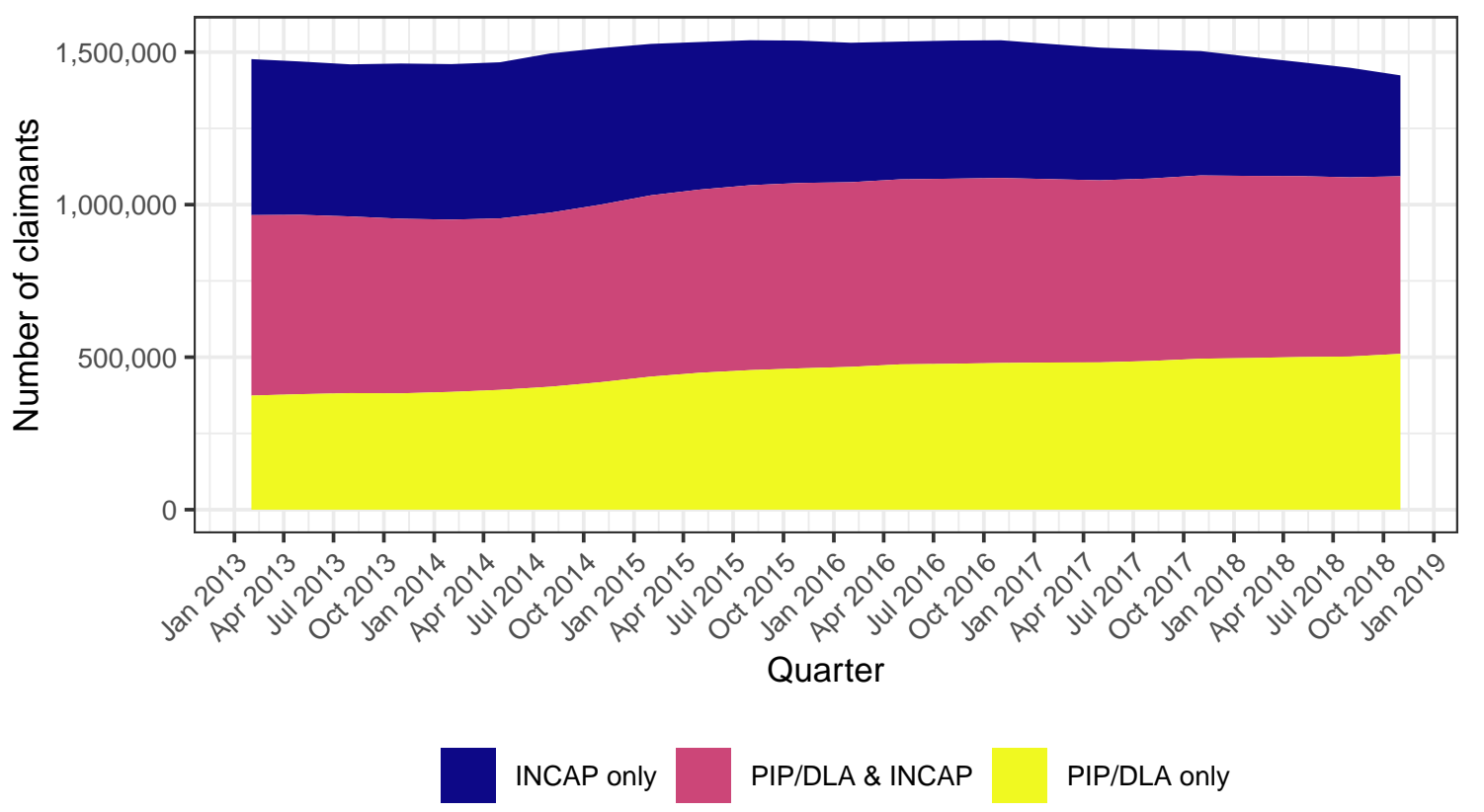

(c) Evan Odell | 2019 | CC-BY-SA

Figure 2: Total of one group of working-age disability benefit recipients receiving the other type of working-age disability benefit

$64 \%$, were also in receipt of PIP/DLA. Just over half - 53\% - of PIP/DLA recipients also received incapacity benefits over the save period.

Both benefits involve a points-based assessment of an applicant's health and physical, mental and sensory capacities, that determines eligibility and the value of benefit payments and in the case of ESA the conditions attached to benefit receipt. Both benefits emphasise what an applicant cannot do, awarding points for deficiencies, with enough deficiencies of various severities determining what, if any, cash benefit the applicant will receive. This can have the peverse effect of punishing applicants for effectively managing their disability or health condition.

\subsection{Personal Independence Payment}

The Personal Independence Payment benefit was introduced in 2013 (with full roll-out in 2014), replacing the older Disability Living Allowance (DLA), and included the re-assessment of DLA recipients under PIP criteria, a process that as of July 2019 is still ongoing. As of February 2019, the most recent data available, there are 587,942 people eligible for DLA, and 576,404 receiving payments, the remainder having their payment suspended due to hospital stays or other unreported reasons.

PIP is a purely needs-tested benefit providing payments to working age (16-64) disabled people to assist with additional financial costs resulting from their disability, and it does not take into account a claimant's earnings from work or other sources, the value of any savings, or their household situation. Applicants are assessed on two sets of criteria (called "descriptors"), covering their ability to perform certain tasks (the "Daily Living Activities") and to move around ("Mobility" descriptors). A score of eight points or higher entitles in a given category entitles applicants to the "standard rate" of benefit for that category, and 12 points or higher entitles applicants to the "enhanced rate" (Department for Work and Pensions 2019b). The weekly and annual value of each award rate for the most current financial year is in Table 1. 


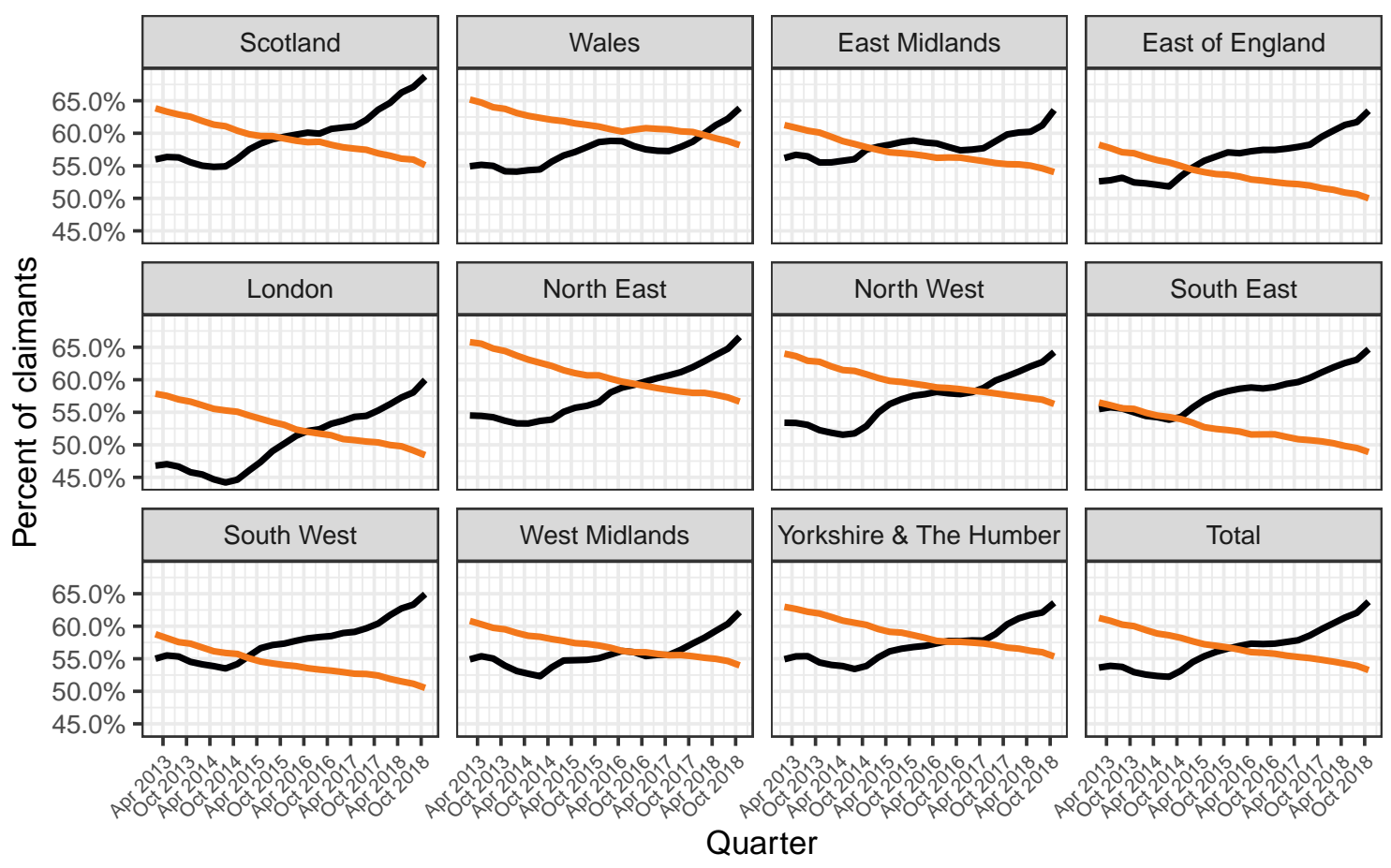

Percentage of INCAP recipients also receiving PIP/DLA

- Percentage of PIP/DLA recipients also receiving INCAP

(c) Evan Odell | 2019 | CC-BY-SA

Figure 3: Percentage of one group of working-age disability benefit recipients receiving the other type of working-age disability benefit, by UK region

Table 1: Personal Independence Payment Award Rates

\begin{tabular}{l|r|r}
\hline PIP Category & Amount per Week 2019/20 & Amount per Year 2019/20 \\
\hline Daily living - standard rate & $£ 58.70$ & $£ 3,060.79$ \\
\hline Daily living - enhanced rate & $£ 87.65$ & $£ 4,570.32$ \\
\hline Mobility - standard rate & $£ 23.20$ & $£ 1,209.71$ \\
\hline Mobility - enhanced rate & $£ 61.20$ & $£ 3,191.14$ \\
\hline
\end{tabular}




\subsection{Employment and Support Allowance}

Employment and Support Allowance (ESA) is a means- and needs-tested benefit for people who are not working due to disability or ill health. ESA applicants with household earnings or savings above various thresholds are ineligible for the benefit. ESA was introduced in October 2008 to replace Incapacity Benefit (IB) for new claimants, and existing recipients of IB began to be reassessed for ESA in March 2011, a process that reassessed 1,480,400 people by June 2018 (the most recent figures available). As of November 2018 there were only 51,354 people still receiving IB, representing $40 \%$ of those receiving IB when ESA was introduced and $58 \%$ of the total recipients when ESA assessments began.

ESA eligibility requires the identification of a specific cause of poor health or disability (The Employment and Support Allowance Regulations 2013 2013). ESA is broken into two types: contributory-based, where eligibility is based on having paid a certain amount in National Insurance, and income-based, which has been incorporated into Universal Credit. People awarded ESA are placed into one of two categories: the Work-Related Activity Group (WRAG) or the Support Group (SG). Claimants placed in the WRAG have to undertake work-focused interviews and attend job-centre appointments, and can be sanctioned if they fail to do so. Claimaints in the support group do not have to undertake these activities. The exact amount of ESA paid depends on the type being claimed, the category claimaints are placed in, and their living situation, including savings, partner's earnings and other sources of income (see Greaves 2019, 68-94).

\subsubsection{The Work Capability Assessment}

Eligibility for ESA is based on the Work Capability Assessment (WCA), a two stage assessment process. The first stage assesses applicants on two series of criteria - a 10 criteria physical disabilities category and a seven criteria mental, cognitive and intellectual functions category - to determine if applicants have a "limited capability for work" (see Greaves 2019, 83-85). If applicants meet the 15 point threshold in one or both categories they are declared to have a "limited capability for work", and are otherwise declared "fit for work". If applicants fit some specific criteria they are declared to have a "limited capability for work-related activity", and placed in the support group. Applicants scoring 15 or more points, but not meeting any of the automatic criteria for the support group, are assessed on an additional set of criteria, the "limited capability for work-related activity assessment", to determine if they are placed in the Work-Related Activity Group or the Support Group (see Greaves 2019, 81-85).

See Figure 4 for all ESA group assignments by medical condition, after appeal outcomes have been completed.

\subsection{Scepticism and Hostility}

There were multiple intertwined motivations behind the development and implementation of the contemporary disability assessment processes, the culmination of a long-running process of increasing coercion and conditionality in the British benefits system that began with the introduction of Job Seekers Allowance in 1996 (Fletcher and Wright 2018). Welfare reforms have sought to reduce overall welfare spending by raising the impairment bar for disability benefits, respond to public and media concerns about benefit fraud by reducing the number of "undeserving" benefit claimants (Briant, Watson, and Philo 2013) and move more people into paid employment as part of a "work first" welfare agenda (Lindsay, McQuaid, and Dutton 2007).

As a consequence of these reforms, disability benefit applicants report that claims they make about their disability and its impact on their daily life and ability to work are treated with scepticism throughout the assessment process. Claimants report medical evidence being ignored, and assessment reports including false and inaccurate claims (see research by journalist John Pring 2017). As benefit reforms have focused on reducing the overall cost of disability benefits and reducing fraud, the assessment process is weighted in favour of denying applicants; not only has the assessment adopted a "non-disabled until proven otherwise" outlook, assessors actively disregard evidence that claimants do in fact have the disabilities they claim to. Although it is undeniable that disability benefit fraud exists as a phenomenom, there is no evidence that it is widespread in the UK, or that it ever has been.

The DWP uses an overly generous definition of fraud ("the claimant can reasonably be expected to be aware of the effect [of their personal status] on entitlement" Department for Work and Pensions 2019a, 7), making 

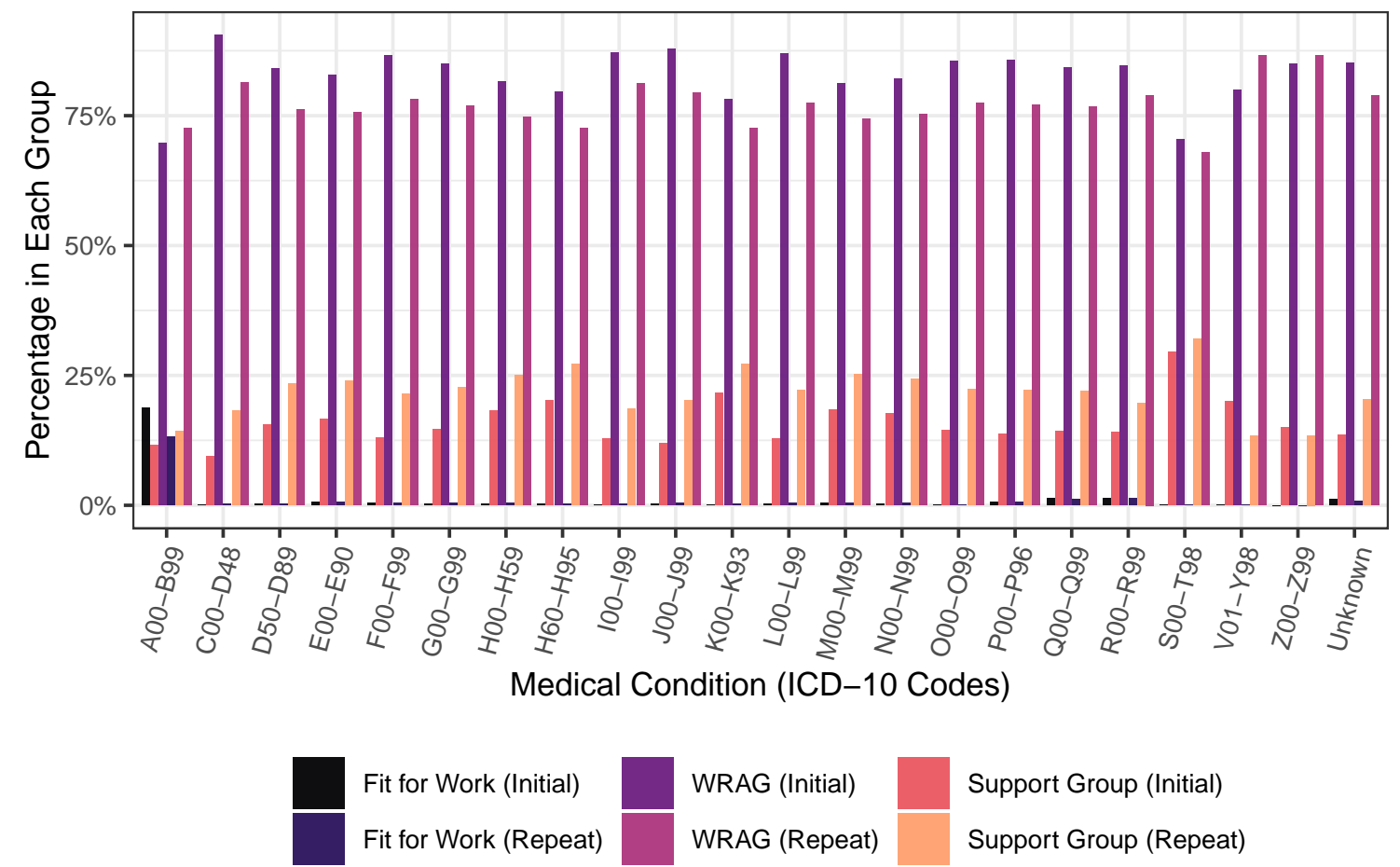

Figure 4: ESA Group Assignment, by Medical Condition and Initial or Repeat Assessment

it likely that given the complexity of the benefits system results in many honest mistakes being classified as fraud. Nevertheless it has never made up up more than $1 \%$ of the total expenditure on disability benefits, and underpayment, due to official or claimant error, remains a much larger problem than overpayment for fraud, claimant error or official error.

Discussion about the balance of disability benefits assessments must consider the social impact of orientations in favour of false positives or false negatives. The human costs of false negative assessments can be considerable; claimants are denied potentially cash benefits that allow them to live independently, they can be forced into work despite severe health conditions, further exacerbating their health and reducing their life expectancy, and the introduction of stricter criteria for disability assessments has been linked to increased suicide rates (Barr, Taylor-Robinson, Stuckler, Loopstra, Reeves, and Whitehead 2016).

The famous formulation of English jurist William Blackstone that, in the case of criminal law: "[i]t is better that ten guilty persons escape than one innocent suffer" (Blackstone 1775, 4:358), and his formulation, or some variation of it, can be applied to the disability benefits system. The harm caused to both individuals and societies of someone who needs disability benefits to survive, or to be a full citizen of that society, is far greater than the harm of "undeserving" people receiving relatively meagre benefits.

Shifting the focus of assessments towards eliminating false negatives, rather than false positives, would have several additional positive externalities. The process of gathering medical evidence for benefits applications, and completing lengthy and potentially confusing application forms, is a time-consuming, stressful [check out that work on stress in re-applications] process that provides no social benefit. Combined with the pressure that applications put on advice services and the lengthy process of assessing applications, the disability benefits system seems designed to ensure that hundreds of thousands of people spend hundreds of thousands of hours doing work with no social utility to speak of, and in the case of applicants and charity volunteers, no individual utility. It is likely that a less sceptical system will save money, or allow financial resources to be redistributed in a more useful manner. 


\subsection{Accuracy and Accountability}

It is unclear if support for the welfare state depends on perceptions of fairness, and the (perceived) deservingness of the people subject to unfair treatment. Nonetheless, policy makers should be concerned with the views of current and potential service users and benefit claimants. There are two potential types of error that can be made when determining elgibility: Type I errors - false positives - and Type II errors - false negatives.

Under the current disability benefits system, the department responsible for their administration - the Department for Work and Pensions (DWP) - has no incentive to reduce false negatives, but strong incentives to reduce false positives, including the costs of benefit payments and popular belief in high rates of fraudulent benefit claims. Benefit claimants are subject to hostility, with surveillance, scepticism and detterence the driving force behind policy decisions, what Fletcher and Wright (2018) labelled the "wholesale criminalisation of benefit receipt". Rather than attempting to tackle popular perceptions towards benefits and their recipients through "mythbusting" (which Baumberg Geiger and Meueleman 2016 describe as a futile task in the face of hardened attitudes to welfare spending), anyone seeking to improve the treatment of benefit recipients should focus on the treatment of benefit recipients, not the discourse about them.

\subsection{Application and Appeals}

Determining the extent to which any given individual is disabled and faces barriers to employment and/or additional costs as a result of disability is a technically complex task. However, the DWP and its contractors appears uniquely incompetent at it. Figure 5 shows PIP award rates by the DWP, by major disability category from April 2013 - April 2019 for reassessments and non-reassessments. Figure 7 shows the success rates over time for major disability categories (note that there are periods of time with no reported clearances for specific disabilities). Figure 6 shows the overall PIP award rate for all disabilities from April 2013 - April 2019 (excluding awards made after appeal). The award rate for non-reassessed applications has been under $50 \%$ since the beginning of 2015, while the award rate for reassessments has also declined to the point where less than two-thirds of reassessments results in PIP being awarded in the most recent available months.

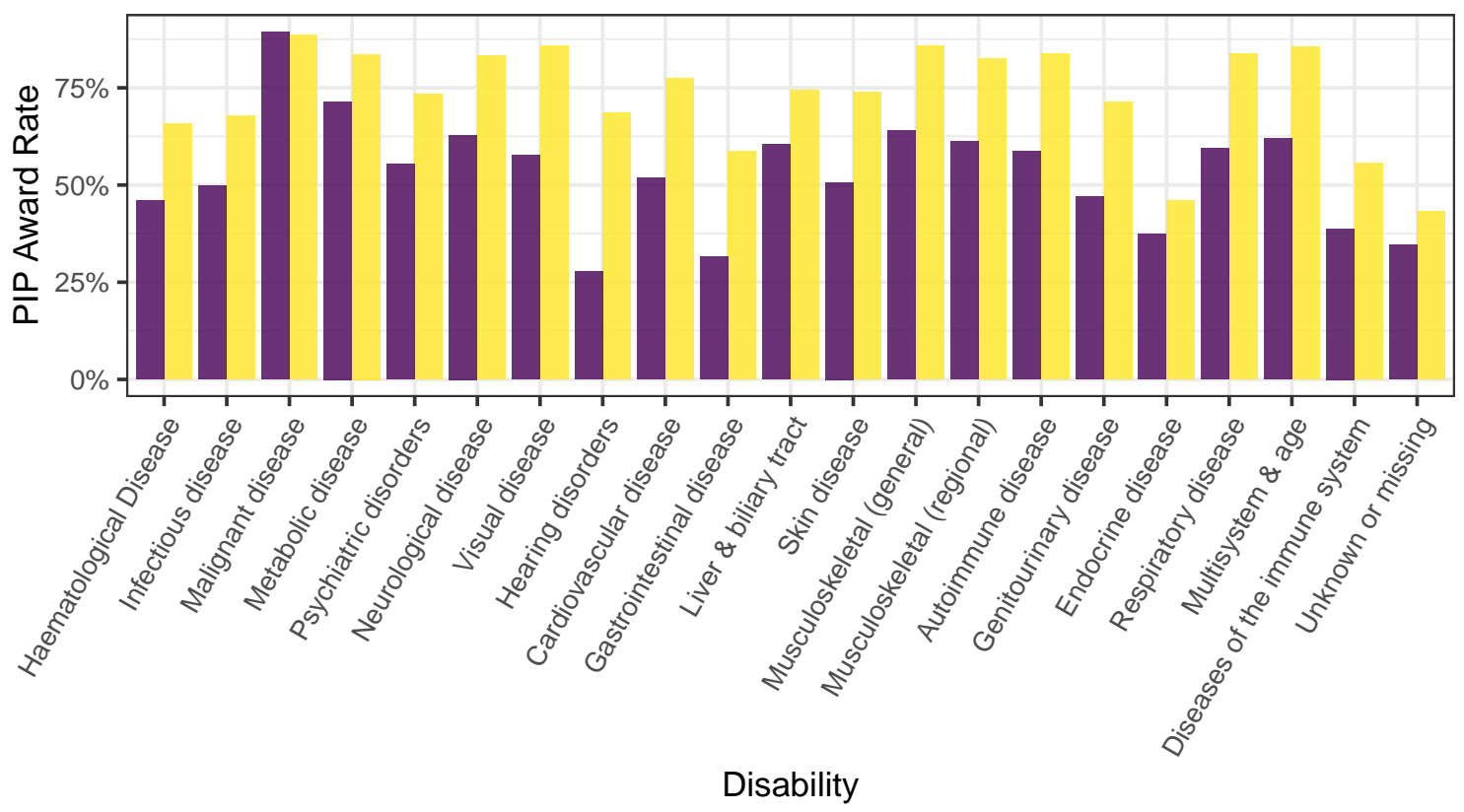

Not Reassessment

Reassessment

Figure 5: Overall Success Rate on PIP Applications by Main Disability Category

Disability benefit appeals make up the majority of the case load of UK social secruity tribunals (Figures 


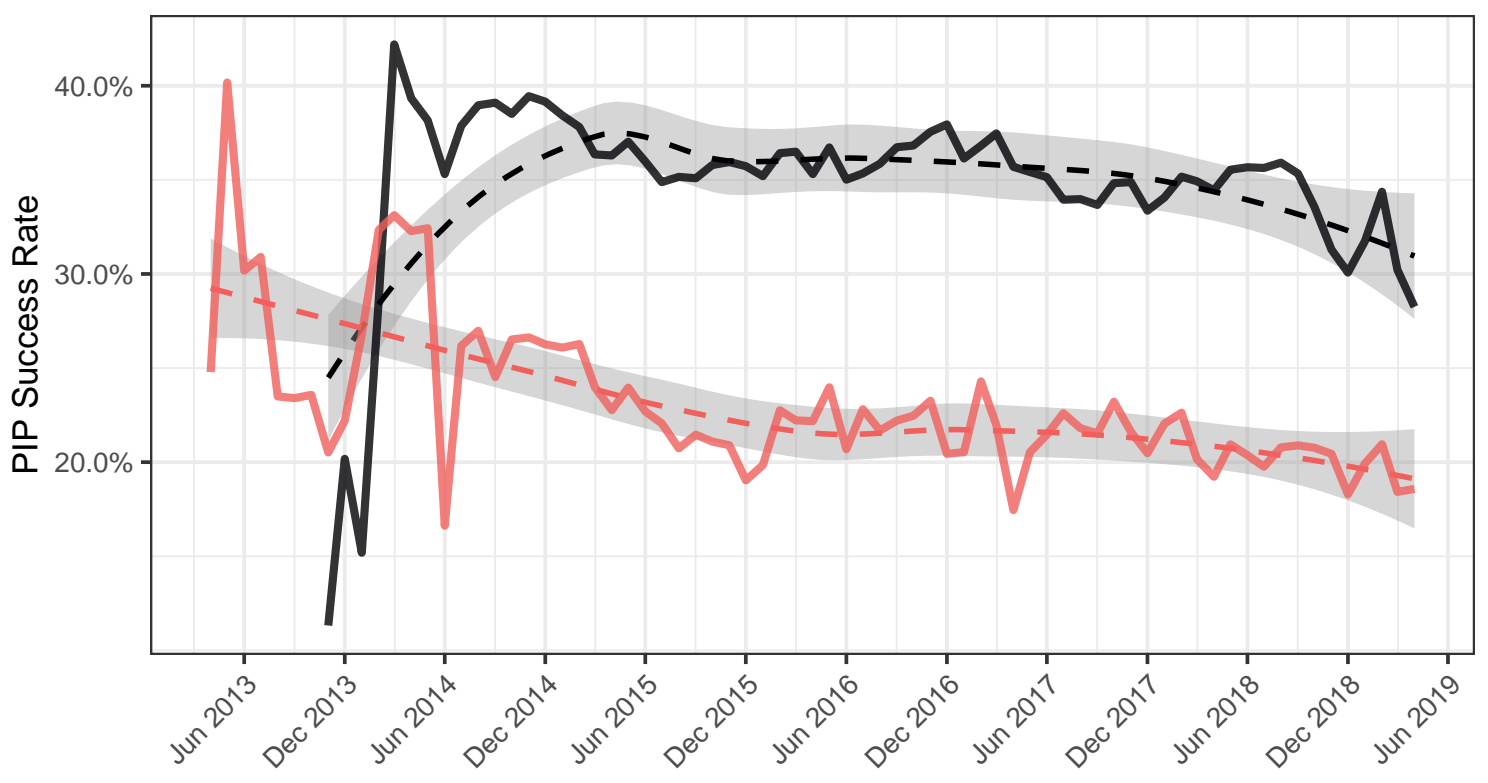

Not Reassessment $=$ Reassessment

Figure 6: Overall Success Rate on PIP Applications, April 2013 - April 2019

8 and 9). Of the 3,561,549 cases heard by the courts between Quarter 1, 2009/10 and Quarter 4, 2017/18, $1,758,483$ or $49 \%$ of all cases, were ESA appeals. Disability benefits appeals (PIP, ESA, DLA, Attendance Allowance and Incapacity Benefit) make up $83 \%$ of all cases heard by the tribunal in this time.

Since their respective introductions, Employment and Support Allowance (ESA) and Personal Independence Payment (PIP) have made up the largest proportion of appeals. In 2017-2018, almost half of all social security appeals have been over PIP, while from 2013-2014, over two-thirds of all appeals were on ESA decisions, as the government moved most Incapacity Benefit claimants to ESA. In 2013-14, tribunals heard 308,050 appeals on ESA decisions, of which $44.3 \%$ where successful.

There is a large drop in appeal volumes, beginning in April 2014. In the year 2013/14 there were 371,411 disability benefit appeals, compared to 83,120 the following year, a drop of $77.6 \%$.

There are two reasons for the reduced appeal volume. The first is the completion of the bulk of the reassessments of Incapacity Benefit (IB) claimants being moved to ESA in 2014, and the appeals associated with the migration. The reassessment of IB claimants has been linked to increased mental health issues, including suicides (Barr, Taylor-Robinson, Stuckler, Loopstra, Reeves, and Whitehead 2016), and the Work Capability Assessment (WCA) used to determine eligibility for ESA has been widely criticised by campaigners and academics (see Baumberg Geiger et al. 2015; and Barr, Taylor-Robinson, Stuckler, Loopstra, Reeves, Wickham, et al. 2016 for an overview of these criticisms), and in five independent reviews (Harrington 2010, 2011, 2012; Litchfield 2013, 2014).

The second reason for the decrease is that the DWP made appealing more difficult in 2013, through the introduction of mandatory reconsiderations. Mandatory reconsiderations formed part of the PIP process from its inception in April 2013, and were extended to cover ESA applications made from October 2013. Prior to April 2013, appeals were made directly to the DWP, and then heard by the Tribunal Service. Since April 2013, applicants have to appeal directly to the Tribunals Service, and the Tribunals Service only accepts appeals if applicants have asked the DWP for a mandatory reconsideration. This delays the appeals process itself, and the DWP only changes its decision in roughly one-fifth of both ESA (Devaney 2018) and PIP (Arrowsmith 2018) mandatory reconsiderations. The introduction of mandatory reconsideration appears to 

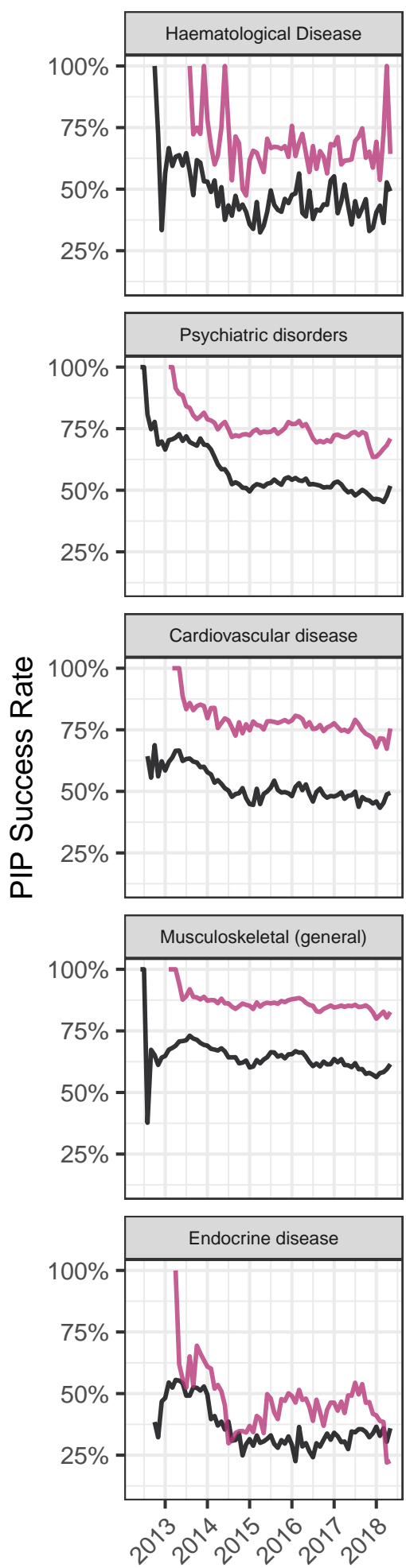
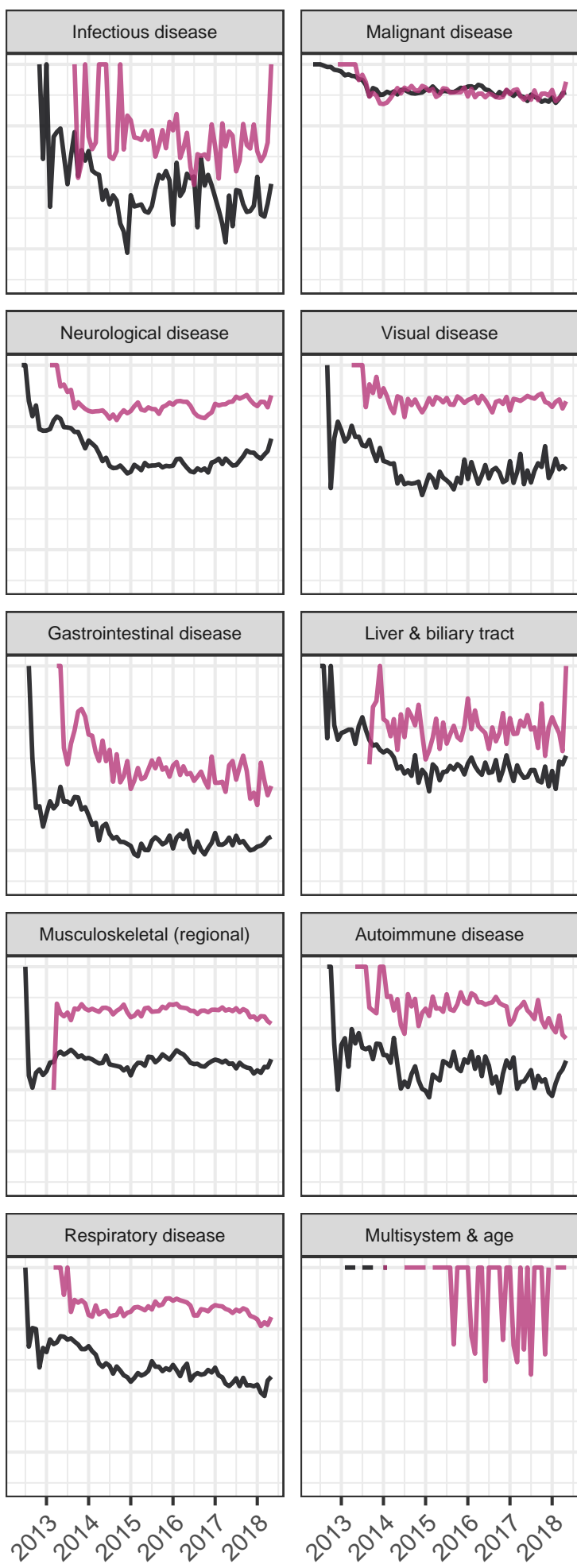
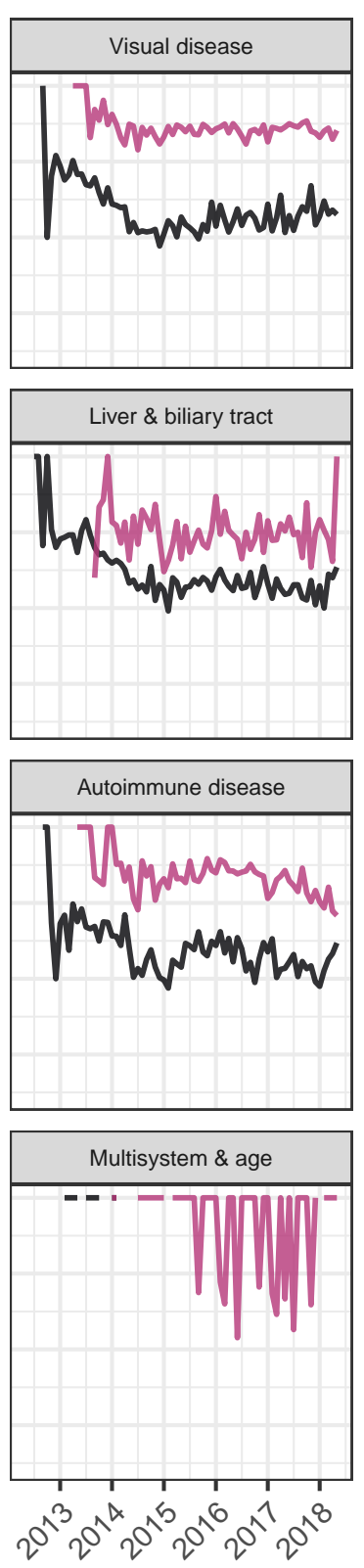
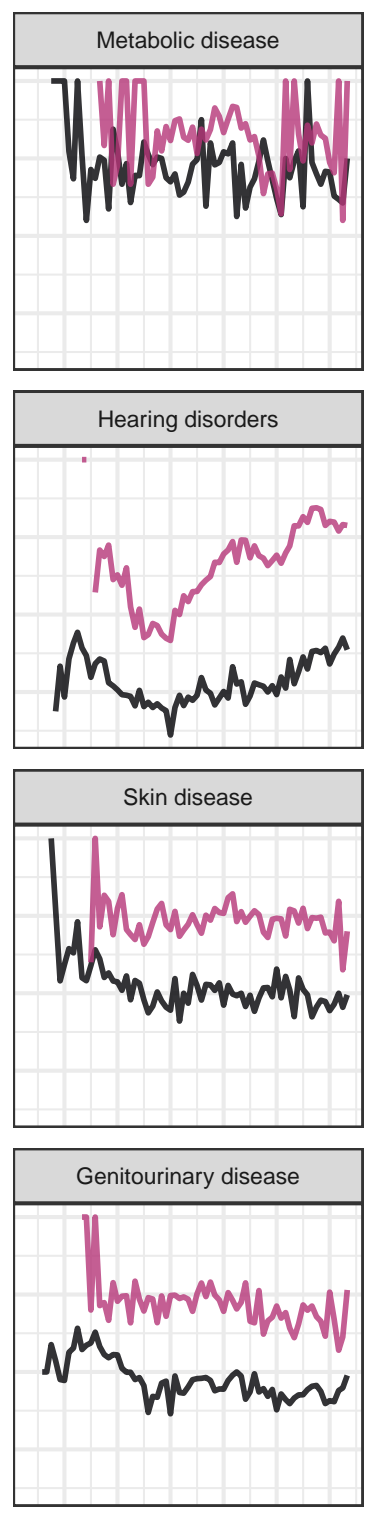

Diseases of the immune system

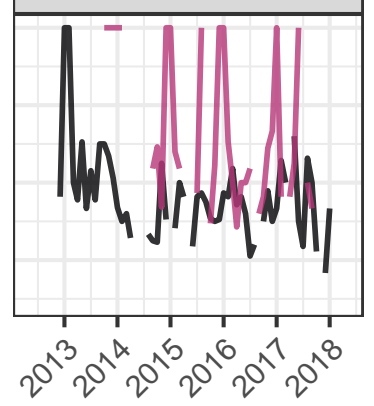

- Not Reassessment — Reassessment

Figure 7: DWP PIP Award Rates by Major Disability Category 


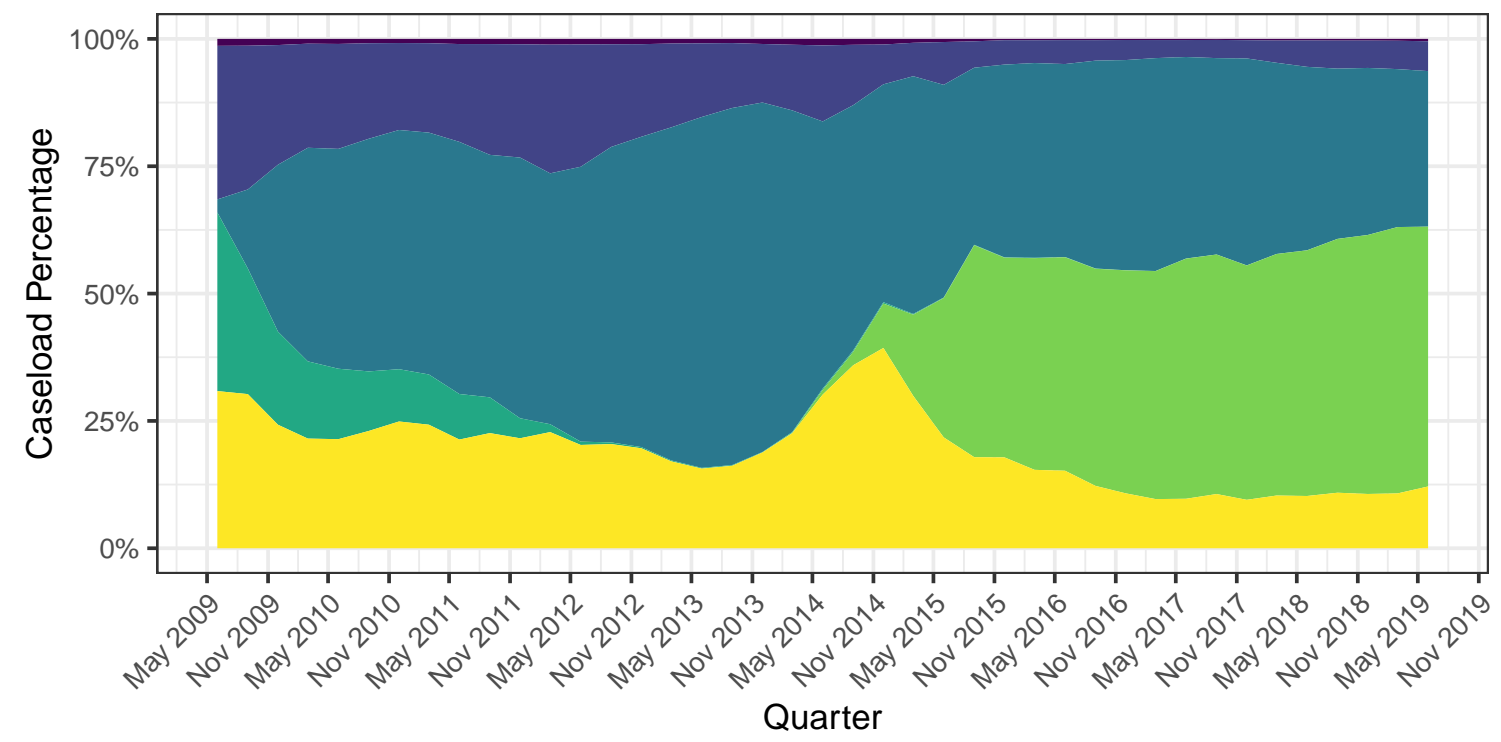

Attendance Allowance

Disability Living Allowance

Employment and Support Allowanc

Incapacity Benefit

Personal Independence Payment

Other

Figure 8: Caseload Distribution, First Tier Social Security Tribunals

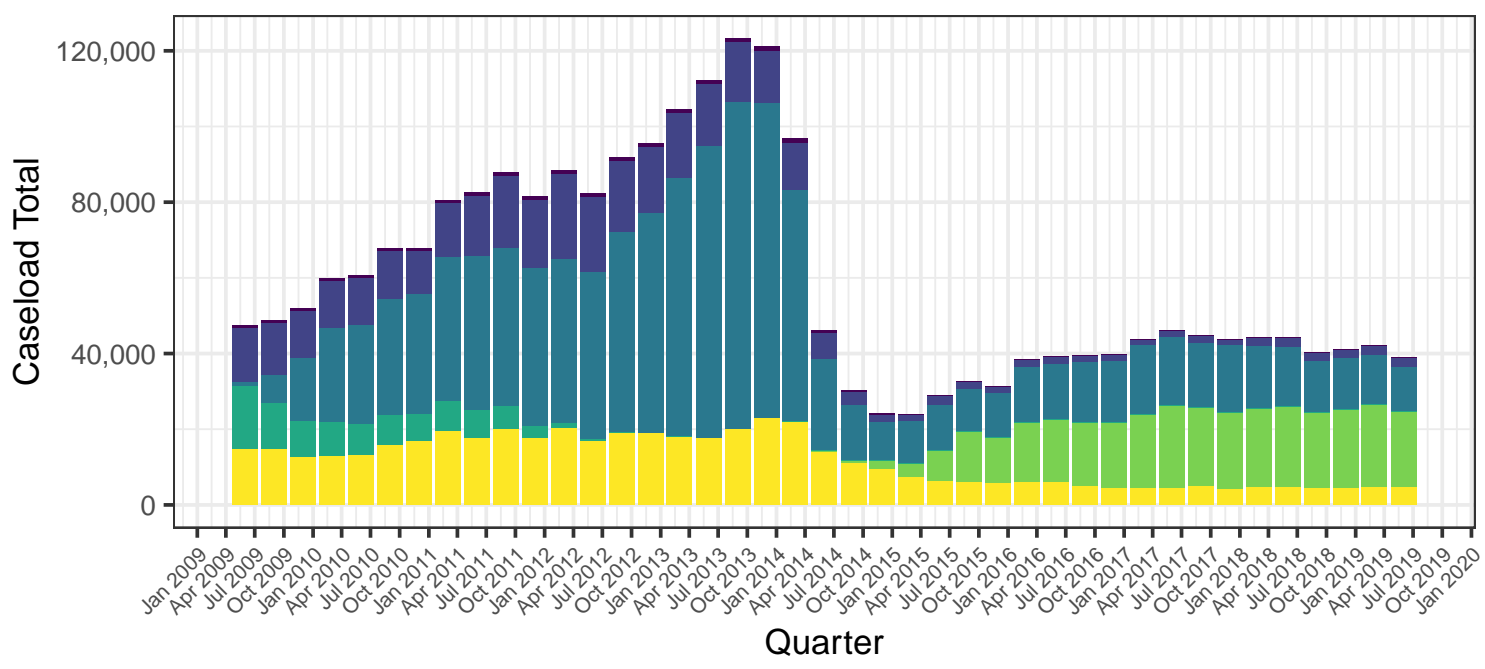

Attendance Allowance

Disability Living Allowance

Employment and Support Allowance

Incapacity Benefit

Personal Independence Payment

Other

Figure 9: Caseload Totals, First Tier Social Security Tribunals 
have led to large a drop in the number of appeals, alongside an increase in the success rates on appeal. The increased administrative burden of appealing has likely deterred many applicants who would be successful from appealing DWP decisions to the Tribunal.

\subsection{Chokepoints}

There is no evidence to suggest that applicants who appeal to tribunals are meaningfully different from those who do not appeal, at least as far as their disability or health condition is concerned. Rather they are applicants in a position to navigate the administrative system to their own benefit, are able to turn the weaponised paperwork (Davies 2018) of the benefits application system back upon the DWP. There are several stages in the applicant journey where they can be wrongfully denied benefits, or dissuaded from applying:

1. Pre-application. The chilling effect of media discourse about disability benefit claimants (most associated with but not restricted to the tabloid press) can dissuade people from applying. The internalisation of one's own status as "undeserving" of support, the belief that they will not be eligible, as well as the extensive work and humilation involved in submitting an application is likely to dissuade many people.

2. The application. Both the PIP and ESA applications are lengthy, and often irrelevant to a person's actual experience of ill-health or disability. Likewise the need to gather documentation from doctors, carers, friends and family can be time-consuming, and much of this evidence seems to be ignored.

3. The assessment. As discussed elsewhere, assessment reports are often inaccurate.

4. Reconsideration. While mandatory reconsideration requires relatively little paperwork, many disabled people may just want to move on with their lives, particularly if they have been awarded something, even if it is much less than they actually need.

5. Tribunals. The process of going to tribunal, which involves even more paperwork and lengthy delays, is a further hurdle. Access to advice and support is varied, and many disabled people may simply decide they do not have the time or energy to appeal.

\subsection{Success on Appeal}

Disability benefit appeals have high success rates, and the rates at which tribunals overturn DWP decisions in favour of disability benefit claimants has increased over time for both ESA and PIP. The volume of appeals has declined, particularly from 2013/14 when the process of moving claimants to ESA was largelly completed.

\subsubsection{ESA}

Figure 10 shows the success rate on appeal of ESA applicants, while Figure 11 shows the total volume of applicants, and the number having the decision made by the DWP overturned.

The DWP publishes some statistics on initial and final decisions regarding ESA group placement. Figures 12 and 13 show the changes in ESA group placement from initial decision to after appeals have been completed.

Figure 12 shows that the largest changes after appeal are in the number of people initially found Fit-for-Work being moved into the Work-Related Activity Group, or in some cases the Support Group. Note that the Y-axis in Figure 13 is not consistent across each year to account for the variations in WCA caseloads.

\subsubsection{PIP}

Figure 14 shows the ever-increasing overturn rate of DWP PIP decisions at tribunal.

In the case of PIP, details are not available on the decisions made by the DWP overturned by tribunals. It is unclear how many appeals are from claimants who were awarded benefits, but believe they should have been awarded the higher rate instead of the standard rate, or were wrongly denied one component (e.g. only 


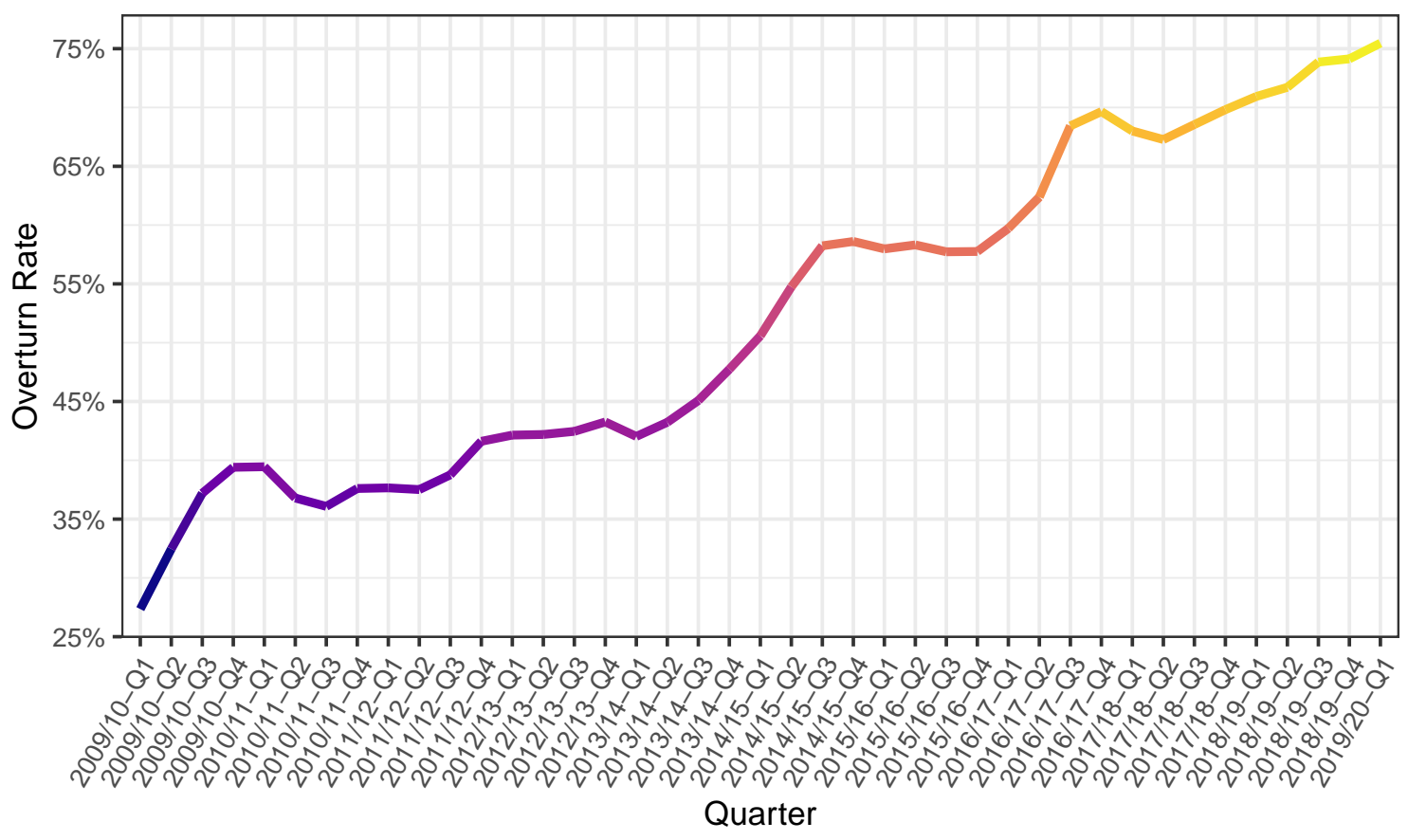

Figure 10: Employment and Support Allowance Appeal Overturn Rates

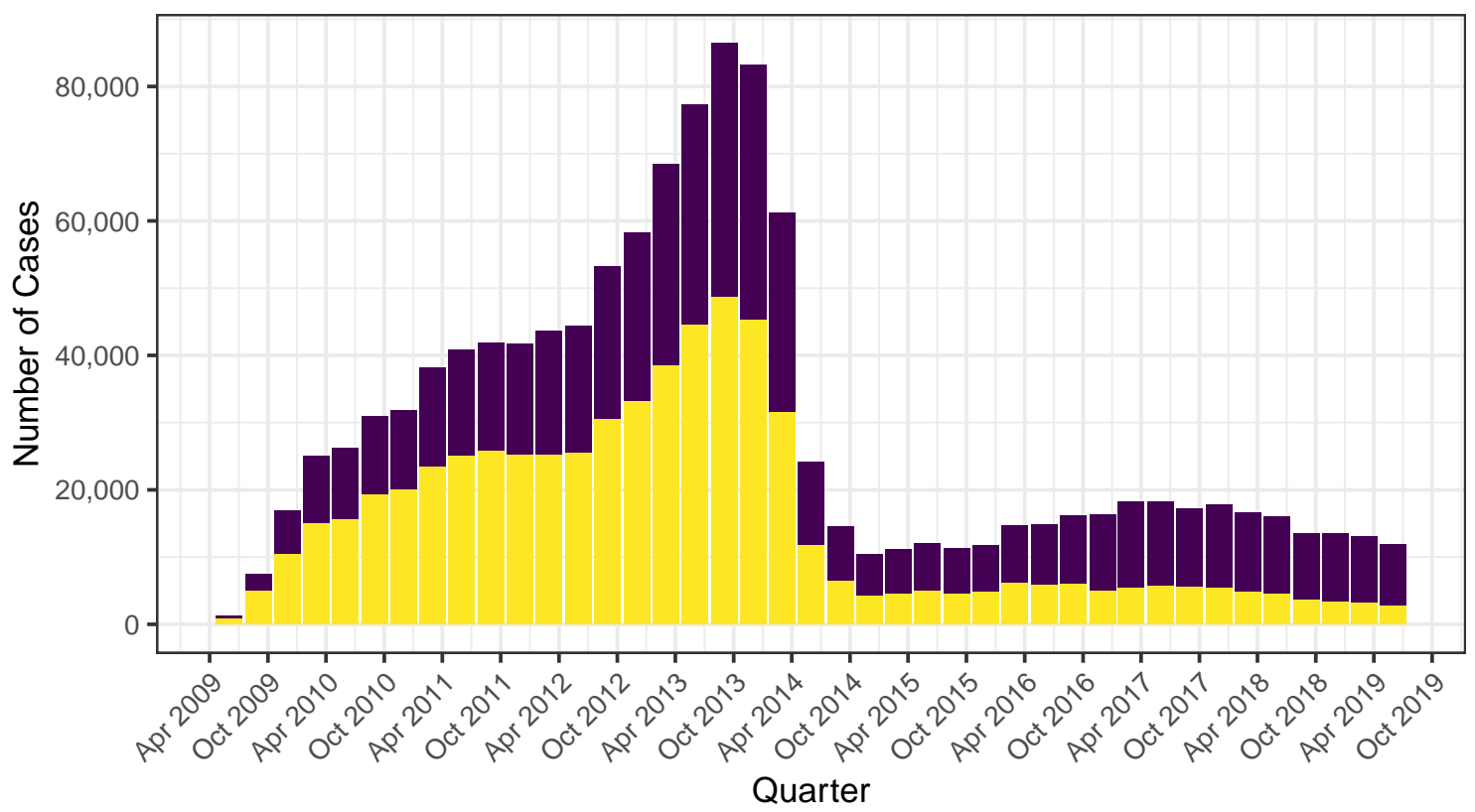

Decision In Favour

Decision upheld

Figure 11: Employment and Support Allowance Appeal Outcomes 

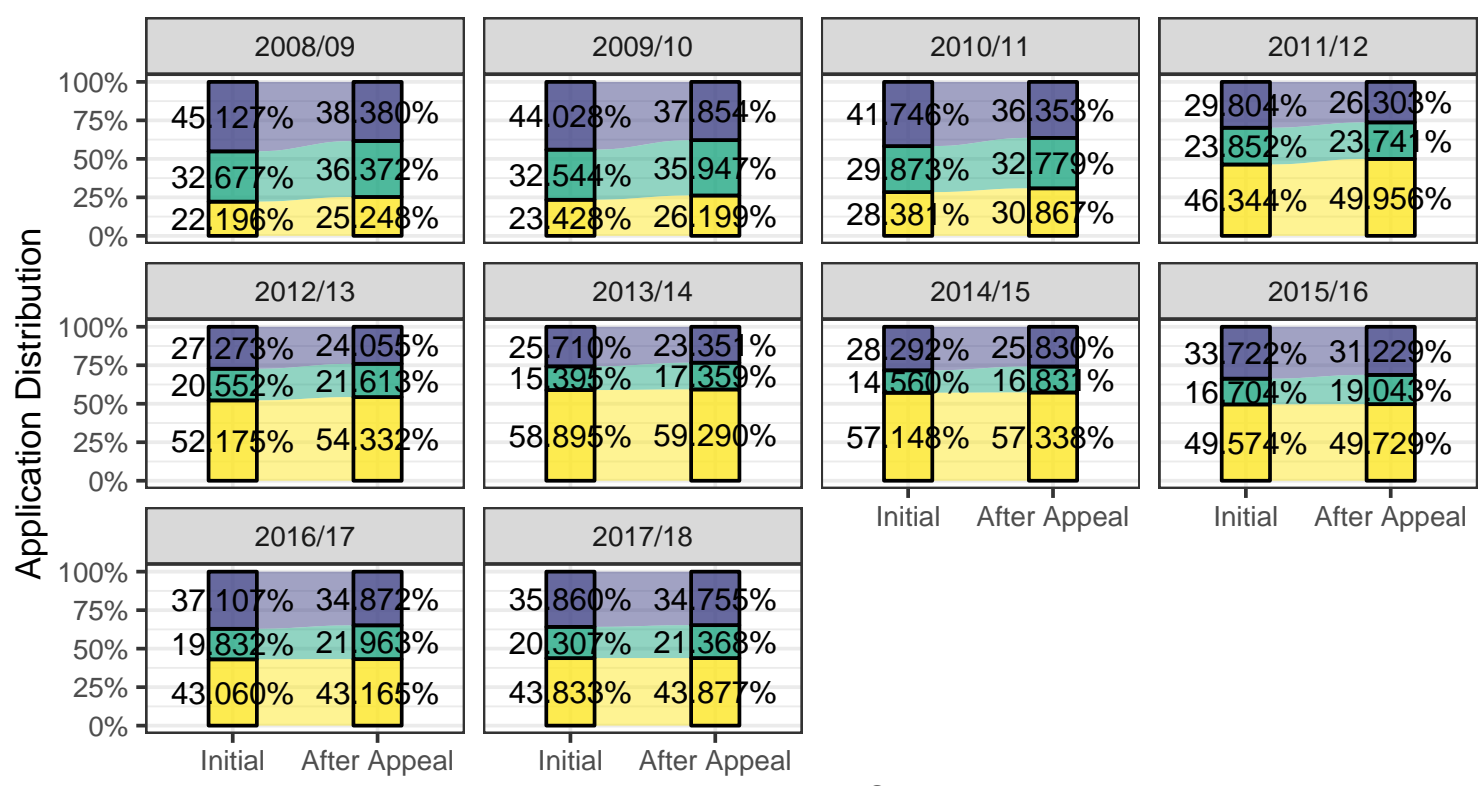

Assessment Stage

Fit for Work

Work Related Activity Group

Support Group

Figure 12: ESA Outcomes Before and After Appeal
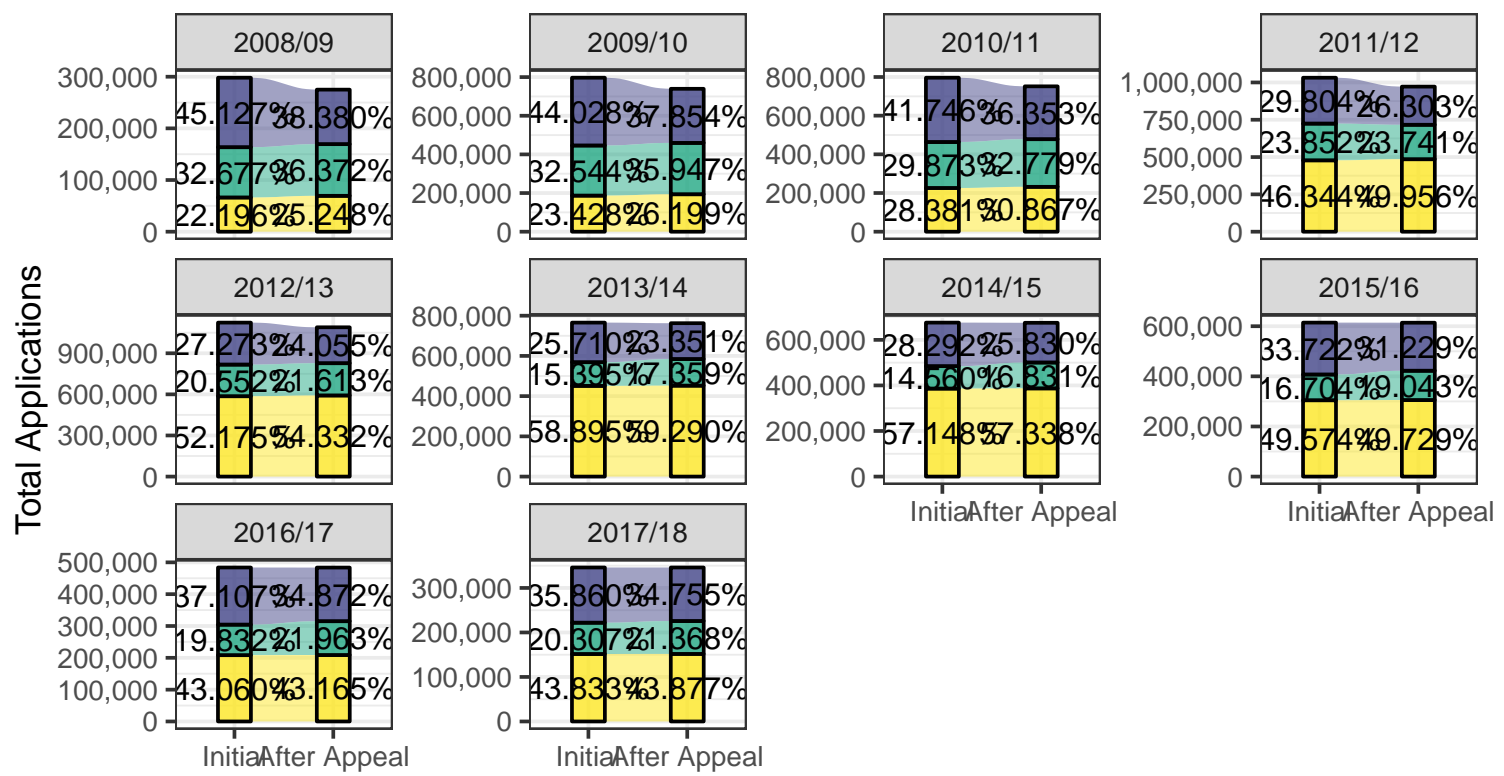

Assessment Stage

Fit for Work Work Related Activity Group Support Group

Figure 13: Total ESA group placements before and after appeal 


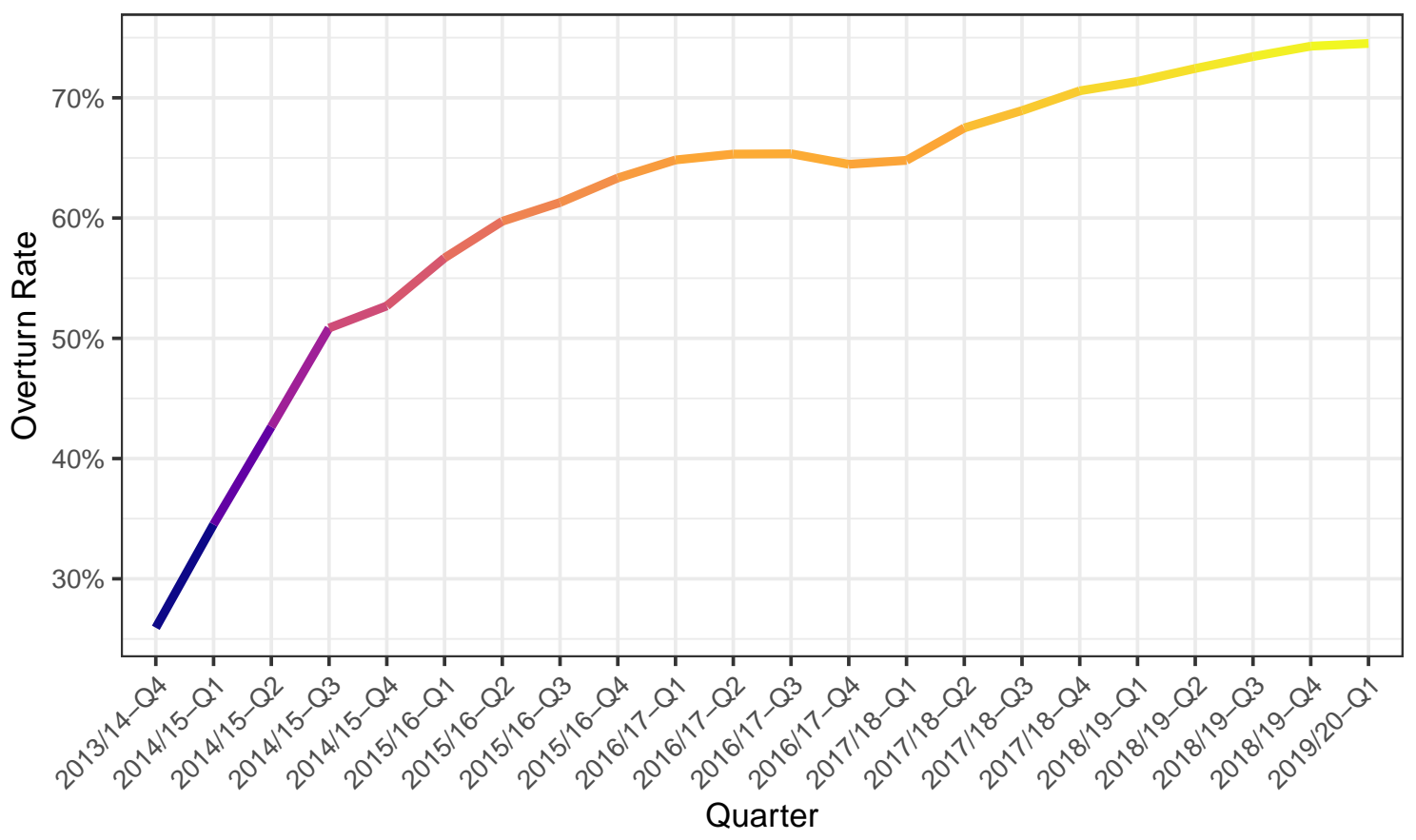

Figure 14: Personal Independent Payment Appeal Overturn Rates

awarded mobility PIP but not daily living PIP), and how many are from people denied any award in their initial application.

\subsection{Clearance Times}

Tribunal clearance times have also been increasing (Figure 15), with PIP and ESA appeals taking an average 30 or more weeks in the most recent quarter. Reducing the case load of tribunals will save the tribunals service money, and make the appeals process shorter for those who do have to go to appeal.

\section{Why compensate?}

It is reasonable for a person - when they have been unfairly mistreated by the state and suffered material harm as a consequence - to expect compensation from the state. The UK's track record for compensating victims of miscarriages of justice, police misconduct or other civil rights violations is poor. This suggests that the payment of compensation for people wrongly denied disability benefits would involve both wholesale justice system reform as part of a fundamental reshaping of the relationship between the British state and its citizens - given the UK's ongoing constitutional crisis, such a reshaping is clearly long overdue.

\subsection{Compensation eligibility}

There are some "test cases" - where the appeal is over a question of how the law and regulations should be interpretted, rather than an applicant allegeding that laws and regulations have been misapplied. Should applicants in these cases - such as a recent supreme court decision (Secretary of State for Work and Pensions (Appellant) v MM (Respondent) (Scotland) 2019) - also be eligible for compensation? I see no reason why they should not. They will have suffered the financial hardships resulting from being denied benefits; are only a small handful of appeals (so it may not be worth the cost of separating these applicants from all others); and given that decisions on interpretation of regulations are relatively one-sided, this provides a further incentive for the DWP to craft regulations that are as clear as possible. Additionally, the fundamental aim of the compensation scheme is to shift the assumptions made by the DWP that applicants for disability 


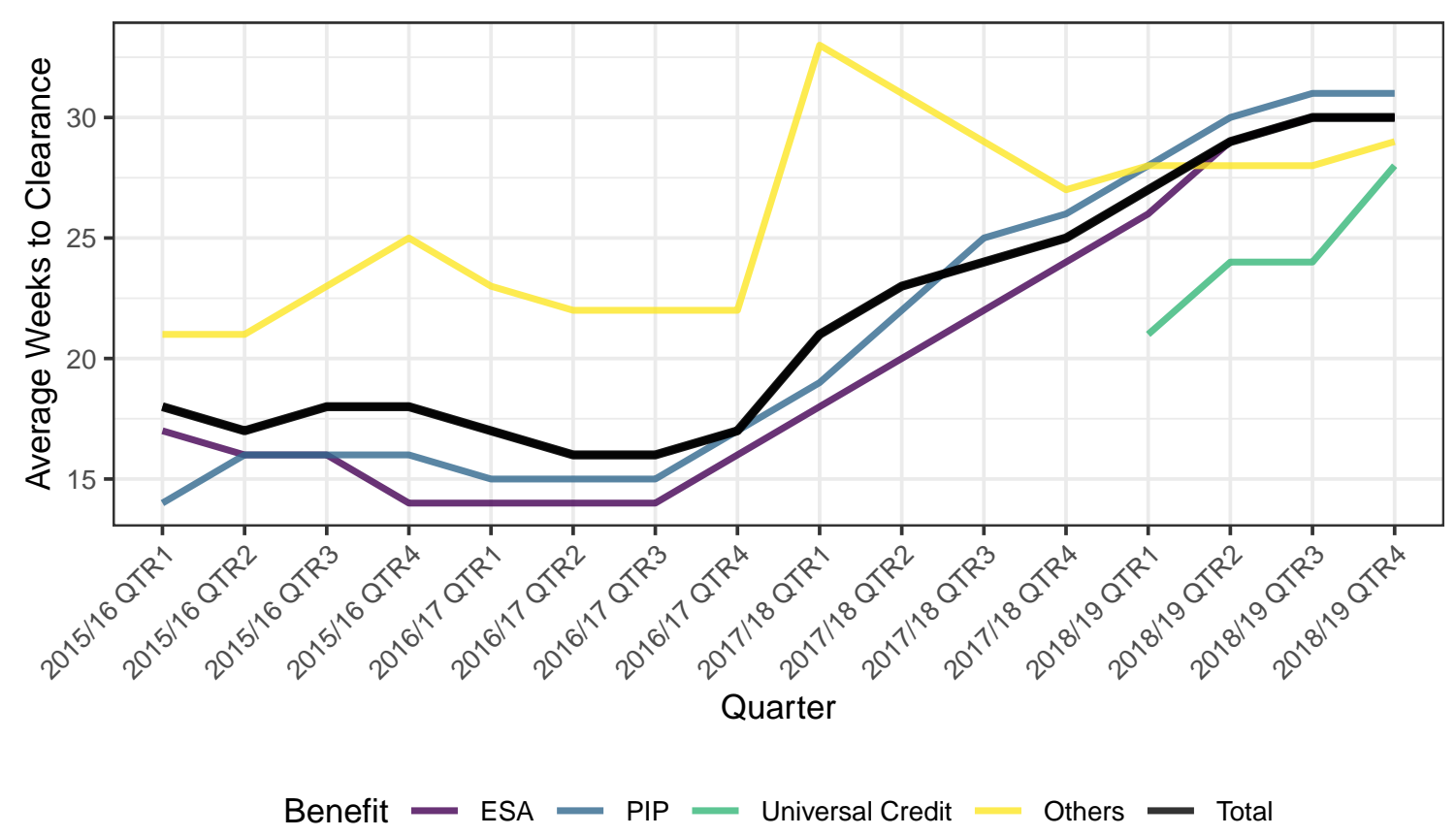

Figure 15: Average First Tier Tribunal Clearance Times

benefits are eligible until proven to be otherwise - it is better to pay relatively small sums of money to people involved in test cases than it is to do nothing while those people suffer financial hardship.

New evidence can be introduced on appeal, although the tribunal can only consider that evidence if it was relevant at the time of initial application - e.g. a medical diagnosis confirmed after the submission of a benefits cannot be considered. As this is the case there should be some leeway for tribunals to decide if an applicant is eligible for compensation; this is particularly the case if an applicant submitted sufficient evidence to the DWP for them to have made a decision with, and the additional evidence provided to the tribunal merely strengthens their case. It is therefore likely there are few instances where a tribunal would award an applicant benefits they had previously been wrongly denied by the DWP, but not determine them to be eligible for additional compensation.

\subsection{Incentives for Accuracy}

There are few incentives for accuracy in to the British disability benefits system. Payment-by-results, where contractors are paid in part on the quality of their work, is not effective in disability benefits system according to the Work and Pensions Select Committee inquiry into PIP and Esa assessments (Work and Pensions Committee 2018), as the complexity of assessments processes and the high reputational risks involved means that a payment-by-results system is unlikely to attract high quality bids. Even without a payment-by-results system, the DWP has reportedly struggled to develop interest in the contracts. Likewise a payment-by-results system can be avoided by bringing assessments in-house.

The incentive for accuracy in benefit assessments must ultimately lie with the DWP, rather than with individual contractors. As it stands, the DWP has little financial interest in ensuring accuracy, and appears to be focused on dissuading people who could be eligible for disability benefits from applying, and treating application with undue scepticism and hostility. Charging the DWP interest on benefit payments when an applicant was improperly denied will produce several positive effects:

1. Being charged interest will provide the DWP with a financial incentive to ensure accuracy in initial assessments, and in cases of mandatory reconsideration and appeal, to have those decisions made as quickly as possible. 
Table 2: DWP's cost-per-appeal

\begin{tabular}{l|r}
\hline Reconsideration/Appeal Type & Cost-per-unit $(£)$ \\
\hline PIP Reconsiderations & 55.07 \\
\hline PIP Reassessment Reconsiderations & 37.89 \\
\hline PIP Appeals inc Training & 211.39 \\
\hline PIP Reassessment Appeals & 93.90 \\
\hline ESA Reconsiderations & 53.69 \\
\hline ESA Appeals & 82.98 \\
\hline
\end{tabular}

2. Charging interest will at least partially compensate claimants for any financial hardships faced as a result of improper initial decisions, as well as for services or opportunities denied applicants because of the delay. Both PIP and ESA come with automatic eligibility for other services and entitlements, such as blue badges. The actual financial impact of an improper denial of benefits will vary drastically between different claimants, but the current system of compensation is less unfair and regressive than the current system.

3. The possibility of more money in case of successful appeal may provide an additional incentive for claimants to appeal. The appeal process can be complicated and claimants who do not know how to construct an appeal and do not have access to advice services may be less likely to appeal. Given the high success rate on appeal it is likely that an increase in the number of appeals will not increase the proportion of unsuccessful appeals by substantial margins.

Paying applicants directly is also preferable to a "polluter-pays" model, or a "payment-by-results" contract for assessment providers. The DWP struggles to find contractors for disability benefit assessments, and increasing the risk to government contractors will not entice new entrants to the market. The DWP can also avoid this problem by bringing assessment services in-house, as has been reccomended by the Work and Pensions Select Committee (Work and Pensions Committee 2018). The DWP can levy "service credits" for poor performance, but it is unclear how they are applied and have been under-utilised in the past (National Audit Office 2016), and the fundamental problems with PIP assessments and the WCA result from their design, not the delivery. Moreover neither polluter-pays and payment-by-results provide any direct compensation to the person most harmed in the case of an incorrect assessment. Just as the state can be required to pay financial compensation to individuals wrongfully imprisoned due to a miscarriage of justice, so the state should pay compensation to individuals denied independence or the necessities of life due to failing in state-controlled services.

The interest charged should be based on some transparent calculation, in keeping with programmes like the student loans scheme, and be high enough to encourage the DWP to change its procedures and ensure a reasonable degree of compensation for claimants. Statistics reported to the Work and Pensions Select Committee indicate the following per-case costs of disability benefit reconsiderations and appeals from the 2016-17 financial year (Work and Pensions Committee 2018, 40-41):

The cost of reconsiderations and appeals to the DWP range from $£ 37.89$ to $£ 211.39$. These statistics do not include the cost of appeals to the tribunal service.

I propose a rate of $\mathrm{CPI}+5 \%$ for the first six months, rising to CPI $+10 \%$ for delays longer than six months, with interest calculated daily (a practice used by amongst others the HMRC). Given that the September 2018 CPI rate (used in calculating changes in disability benefits) was $2.2 \%$, this would results in an annual interest rate of $7.2 \%$ for claims delayed for less than six months, and a marginal rate of $12.2 \%$ for claims with delays of more than six months.

\subsubsection{Delay Examples}

3.2.1.1 31 Week Delay Example The average PIP appeal takes 31 weeks to clear, as of Quarter 4 of 2018/19. A delay of 31 weeks in being awarded the standard rate of PIP ( $£ 58.70$ per week) would mean backpay of $£ 1,819.70$. Under the penalty system, they will receive an additional $£ 137.11$, for a total of 
3.2.1.2 52 Week Delay Example A delay from assessment to award-by-appeal of 52 weeks, when they are awarded the independent living component of PIP. Under the current system, that would result in them receiving backpay of $£ 3,052.40$ ( $£ 58.70$ for each of the 52 weeks of the delay). Under my proposed system, this applicant would receive $£ 3,447.97$, a difference of $£ 395.57$.

The cost penalty of a 52 week delay exceeds the the cost to the DWP of the most expensive appeal by $£ 184.18$, but is more expensive than all appeals except PIP appeals including training costs by at least $£ 301.67$. Therefore for the majority of cases, including all ESA appeals, the DWP has a strong incentive to err on the side of awarding benefits. Requring the DWP to contribute more to the costs of tribunals will provide an even greater incentive to reduce appeals by improving assessment quality.

The time-based interest payments also provide some compensation for applicants who were incorrectly denied benefits, and can help to reduce or eliminate any debt they accumulated while waiting for their benefit payments. It also acts as compensation for the constraints placed upon their life as a result of delays in receiving the money they are entitled to.

\subsubsection{Compensation rates and personal debt costs}

The interest rates I have proposed $(\mathrm{CPI}+5 \%$, CPI $+10 \%)$ are lower than those charged on most credit card or overdraft debt. In the twelve months to 31 July 2019, the average overdraft interest rate was 19\%, and credit card interest averaged 19\%. The Bank of England reports the average interest rate on a $£ 5,000$ personal loan in the twelve months to April 302019 was 8\%, and 4\% for a personal loan of £10,000 (Bank of England 2019, table G1.3). However it is unlikely than anyone applying for ESA, and most people applying for PIP, would be able to access personal loans at single-digit rates.

\section{Conclusion}

The poor accuracy and fairness of disability benefit assessments are serious challenges to the British welfare state. Co-production of those assessments, to better bring an understanding of the lived experience of disability, could help to improve the quality of the assessments themselves. Paying compensation to claimants who are wrongly denied benefits provides a financial incentive to the DWP to ensure that assessments are more accurate, and compensate claimants for the costs associated with being wrongly denied benefits, such as debt, loss of access to support services and additional benefits, and generally reduced quality of life. It also shifts the top-down relationship between state and citizen, providing a financial incentive for the state to retreat from its current stance of scepticism and hostility to disability benefit claimants.

\section{References}

Arrowsmith, Jess. 2018. "Personal Independence Payment: Official Statistics." London: Department for Work and Pensions. https://assets.publishing.service.gov.uk/government/uploads/system/uploads/attac hment_data/file/714950/pip-statistics-to-april-2018.pdf.

Bank of England. 2019. "G1.3 - Average Quoted Household Interest Rates."

Barr, Benjamin, David Taylor-Robinson, David Stuckler, Rachel Loopstra, Aaron Reeves, and Margaret Whitehead. 2016. "'First, Do No Harm': Are Disability Assessments Associated with Adverse Trends in Mental Health? A Longitudinal Ecological Study." Journal of Epidemiology and Community Health 70 (4): 339-45. http://jech.bmj.com/content/70/4/339.abstract.

Barr, Benjamin, David Taylor-Robinson, David Stuckler, Rachel Loopstra, Aaron Reeves, Sophie Wickham, and Margaret Whitehead. 2016. "Fit-for-Work or Fit-for-Unemployment? Does the Reassessment of Disability Benefit Claimants Using a Tougher Work Capability Assessment Help People into Work?" $J$ Epidemiol Community Health 70 (5): 452-58. http://jech.bmj.com/content/70/5/452.short. 
Baumberg Geiger, Ben, and Bart Meueleman. 2016. "Beyond 'Mythbusting': How to Respond to Myths and Perceived Undeservingness in the British Benefits System." Journal of Poverty and Social Justice 24 (3): 291-306. https://doi.org/10.1332/175982716X14721954314968.

Baumberg Geiger, Ben, Jon Warren, Kayleigh Garthwaite, and Clare Bambra. 2015. Rethinking the Work Capability Assessment. London: Demos. https://www.demos.co.uk/files/Rethinking_-_web_1_.pdf.

Benitez-Silva, Hugo, Moshe Buchinsky, and John Rust. 2004. "How Large Are the Classification Errors in the Social Security Disability Award Process?" w10219. Cambridge, MA: National Bureau of Economic Research. https://doi.org/10.3386/w10219.

Blackstone, William. 1775. Commentaries on the Laws of England. Seventh. Vol. 4. 4 vol. Oxford: Clarendon Press.

Briant, Emma, Nick Watson, and Gregory Philo. 2013. "Reporting Disability in the Age of Austerity: The Changing Face of Media Representation of Disability and Disabled People in the United Kingdom and the Creation of New 'Folk Devils'.' Disability $\& 3$ Society 28 (6): 874-89. https://doi.org/10.1080/09687599 .2013.813837.

Davies, William. 2018. "Weaponising Paperwork." London Review of Books, May 10, 2018. https: //www.lrb.co.uk/v40/n09/william-davies/weaponising-paperwork.

Department for Work and Pensions. 2019a. Fraud and Error in the Benefit System: Background Information and Methodology. London: Department for Work and Pensions. https://assets.publishing.service.gov. uk/government/uploads/system/uploads/attachment_data/file/800259/fraud-and-error-statisticsbackground-and-methodology.pdf.

2019b. "PIP Assessment Guide Part Two - the Assessment Criteria." London: Department for Work and Pensions. https://assets.publishing.service.gov.uk/government/uploads/system/uploads/attachmen t_data/file/725533/pip-assessment-guide-part-2-assessment-criteria.pdf.

Devaney, Lottie. 2018. "Employment and Support Allowance: Work Capability Assessments, Mandatory Reconsiderations and Appeals." London: Department for Work and Pensions. https://assets.publishing.se rvice.gov.uk/government/uploads/system/uploads/attachment_data/file/716083/esa-wca-summaryjune-2018.pdf.

Fletcher, Del Roy, and Sharon Wright. 2018. "A Hand up or a Slap down? Criminalising Benefit Claimants in Britain via Strategies of Surveillance, Sanctions and Deterrence." Critical Social Policy 38 (2): 323-44. https://doi.org/10.1177/0261018317726622.

Greaves, Ian, ed. 2019. Disability Rights Handbook: April 2019-April 2020. 44th ed. Disability Rights Handbook 44. London: Disability Rights UK.

Harrington, Malcom. 2010. An Independent Review of the Work Capability Assessment. London: Department for Work and Pensions.

. 2011. An Independent Review of the Work Capability Assessment - Year Two. London: Department for Work and Pensions.

—. 2012. An Independent Review of the Work Capability Assessment - Year Three. London: Department for Work and Pensions.

Heslop, Pauline. 2013. "Disabled People and Their Relationship with Poverty." 23. Working Paper Methods. Bristol: Poverty and Social Exclusion. http://www.poverty.ac.uk/sites/default/files/attachments/WP\% 20Methods\%20No\%2023\%20-\%20Disabled\%20People\%20\%28Heslop\%202013\%29.pdf.

John, Evan, Greg Thomas, and Anel Touchet. 2019. "The Disability Price Tag 2019 Policy Report." London: Scope. https://www.scope.org.uk/scope/media/files/campaigns/disability-price-tag--report-2019updated.pdf.

Lindsay, Colin, Ronald W. McQuaid, and Matthew Dutton. 2007. "New Approaches to Employability in the UK: Combining 'Human Capital Development' and 'Work First' Strategies?" Journal of Social Policy 36 
(4): 539-60. https://doi.org/10.1017/S0047279407001171.

Litchfield, Paul. 2013. An Independent Review of the Work Capability Assessment - Year Four. London: Department for Work and Pensions.

2014. An Independent Review of the Work Capability Assessment - Year Five. London: Department for Work and Pensions.

National Audit Office. 2016. "Contracted-Out Health and Disability Assessments." London: National Audit Office. https://www.nao.org.uk/wp-content/uploads/2016/01/Contracted-out-health-and-disabilityassessments.pdf.

Pring, John. 2017. "PIP Investigation: 200 Cases of Dishonesty... and Still DWP, Atos and Capita Refuse to Act." Disability News Service, August 3, 2017. https://www.disabilitynewsservice.com/pip-investigation200-cases-of-dishonesty-and-still-dwp-atos-and-capita-refuse-to-act/.

Secretary of State for Work and Pensions (Appellant) v MM (Respondent) (Scotland). 2019.

The Employment and Support Allowance Regulations 2013. 2013. SI 2013/379.

Titmuss, Richard. (1968) 2006. "Universalism Versus Selection." In The Welfare State Reader, by Christopher Pierson and Francis G Castles, 2nd ed., 40-47. Cambridge: Polity Press.

Work and Pensions Committee. 2018. "PIP and ESA Assessments." HC 829. London: House of Commons. https://publications.parliament.uk/pa/cm201719/cmselect/cmworpen/829/829.pdf. 